Lee TC, Leung WM, Chan KW. 2006. Climatological Normals for Hong Kong 1971-2000, Technical Note (Local), No. 83. Hong Kong Observatory: Hong Kong; $37 \mathrm{pp}$.

Lee BY, Mok HY. 2010. Potential of Wind and Solar Energy in Hong Kong. Presented in the Symposium on E-Management - Challenges and Opportunities, Hong Kong, 28 May 2010. HKO Reprint No. 965. Lin I, Liu WT, Wu CC, Wong GTF, Hu C, Chen Z, Liang WD, Yang Y, Liu KK. 2003. New evidence for enhanced ocean primary production triggered by tropical cyclone. Geophys. Res. Lett. 30: 1718.

Liu JP. 2006. Actions towards Typhoonrelated disasters reduction in China. IFNet Action Report 2006 for The 2nd General Meeting of International Flood Network (IFNet), Kobe, Japan.
Ryan CJ. 1993. Costs and benefits of tropical cyclones, severe thunderstorms and bushfires in Australia. Clim. Change 25: 353-367.

Song LL, Mao HQ, Qian GM, Liu AJ. 2006. Analysis on the wind power by tropical cyclone. Acta Energiae Solaris Sin. 27(9): 37-40 (in Chinese).

Sriver RL, Huber M. 2007. Observational evidence for an ocean heat pump induced by tropical cyclones. Nature 447: 577-580.

Sugg AL. 1968. Beneficial aspects of the tropical cyclone. J. Appl. Meteorol. 7: 39-45. Water Supplies Department (WSD). 2001. Water for a Barren Rock, Ho P.-Y. (Author Prof.). Commercial Press (HK) Ltd. Wong MS, Kwan WK. 2002. Wind Statistics in Hong Kong in Relation to Wind Power,
Technical Note (Local) No. 77. Hong Kong Observatory: Hong Kong.

World Meteorological Organization (WMO). 2007. High Impact Weather and Climate Events - June 2007, MeteoWorld - December 2007. World Meteorological Organization: Geneva, Switzerland. http:// www.wmo.int/pages/publications/ meteoworld07/_archive/en/dec2007/ impact_weather_june07.html

Zhang Q, Wu L, Liu Q. 2009. Tropical cyclone damages in China 1983-2006. Bull. Am. Meteorol. Soc. 90(4): 489-495.

Correspondence to: Hilda Lam

hildalam@hko.gov.hk

(c) Royal Meteorological Society, 2012

DOI: 10.1002/wea.836

\title{
Cleaner air brings better views, more sunshine and warmer summer days in the Netherlands
}

\section{Aldert J. van Beelen and Aarnout J. van Delden}

Institute for Marine and Atmospheric Research Utrecht, Utrecht University, The Netherlands

\section{Introduction}

In the late 1980s Atsumu Ohmura and several others (e.g. Ohmura and Lang, 1989) discovered that the amount of solar radiation reaching the surface had decreased at many radiation measurement sites between 1960 and 1990. Near densely-populated areas and industries, $30 \%$ less solar radiation was reaching the ground in the 1980s than a few decades earlier (Wild, 2009). However, since the mid 1980s a significant increase in visibility has been noted in western Europe (e.g. Doyle and Dorling, 2002), and there are strong indications that a reduction in aerosol load from anthropogenic emissions (in other words, air pollution) has been the dominant contributor to this effect, which is also referred to as 'brightening'. In the Netherlands visibility, sunshine duration, surface global short-wave radiation and temperature have shown a significant rise during this period, consistent with direct and indirect aerosol effects, implying large regional aerosol effects on climate. The brightening has been stronger during continental windflow than during maritime episodes. This article discusses the evidence for brightening in the Netherlands and its possible connection to the accelerated warming since 1985.

\section{Visibility, aerosols and climate}

The World Meteorological Organization (WMO) gives the following definition of visibility:

Visibility is defined as the greatest distance at which a black object of suitable dimensions (located on the ground) can be seen and recognized when observed against the horizon sky during daylight or could be seen and recognized during the night if the general illumination were raised to the normal daylight level.

In the absence of rain or snow, visibility is largely determined by the aerosol concentration and humidity near the surface. Aerosols are small suspended particles from both natural (e.g. sea salt) and anthropogenic (burning of fossil fuel) sources, and their presence always causes a reduction in visibility due to the scattering of light.

When looking at a distant target, its appearance is altered in such a way that the contrast between the target and the back- ground atmosphere decreases with increasing distance. The distance at which the contrast drops below the contrast threshold of the human eye, and the target becomes barely visible, is defined as the visibility (Horvath, 1981). The visibility of an object varies from observer to observer and with ambient conditions. However, a professional observer can estimate a 'standard' visibility with reasonable accuracy. Recently, visibility has also been determined less subjectively by transmissometers or scatterometers.

The ability of aerosols to scatter light and alter the visibility is strongly dependent on the ambient relative humidity. Aerosols are normally hygroscopic and they take up water when relative humidity is high, increasing their diameters in the process by as much as a factor of four. For example, light scattering per unit mass for an ammonium sulphate aerosol remains fairly constant up a relative humidity of $80 \%$, at which point the particle grows rapidly with an attendant sharp rise in light scattering with increasing relative humidity (Cass, 1979). At relative humidities higher than about $80 \%$ visibility is decreased to what is often called a 'haze'. Relative humidity near $100 \%$ will lead to condensation of water vapour, reducing visibility even further and often leading to fog. Precipitation will also strongly reduce visibility. Therefore, visibility 
can be used as an indicator for changes in aerosol concentrations (Wang et al., 2009); the frequency of good-visibility days is especially suitable for this purpose because it is less sensitive to changes in relative humidity and precipitation (e.g. Gomez and Smith, 1987). It is also not influenced by changes in cloud cover.

There are many ways in which aerosols may influence the climate; the most generally recognized ones are briefly summarized here. Aerosols can change the amount of solar radiation reaching the surface by absorption and scattering (the direct aerosol effect). Certain types of aerosol (e.g. soot) have the potential to change cloud formation by heating atmospheric layers (semi-direct aerosol effect) or by absorption of solar radiation. Aerosols can also influence climate by changing cloud characteristics (indirect aerosol effect), acting as cloud condensation nuclei on which cloud droplets form. Higher aerosol concentrations tend to increase the reflectance (albedo) and lifetime of clouds. These effects are extremely complex and generally considered to be one of the biggest uncertainties in our understanding of the climate system.

Aerosols are removed from the troposphere by precipitation (a process scientists call wet deposition) and sedimentation by gravity (dry deposition). The smallest aerosols (or fine aerosols) tend to have longest lifetimes, because they can only be removed after growing by coagulation. Though globally the largest mass fraction ( $85 \%$ ) of aerosols is of natural origin, aerosols of anthropogenic origin are usually much smaller and thus have longest lifetimes. The observed dominant tropospheric aerosol variations have been attributed to human activities, especially near large population areas and industries. These properties make aerosols a potentially powerful player in the Earth's climate system.

\section{Anthropogenic aerosol emissions}

Many studies have shown that aerosol concentrations are strongly determined by regional sources. Natural aerosol sources mostly consist of sea salt and surface dust, which are relatively coarse particles. They dominate the total aerosol mass, but do not show significant trends. Most of the longterm variation in visibility is caused by human emissions of sulphate aerosols, which have up to ten times greater scattering efficiency per unit mass than larger dust particles, making them the most dominant scattering aerosol in the atmosphere.

A reliable dataset of regular observations of atmospheric sulphur dioxide $\left(\mathrm{SO}_{2}\right)$ concentrations, the precursor of sulphate aerosol, in the Netherlands is available only not cover both the dimming and brightening periods. Nevertheless, the observations clearly demonstrate that the $\mathrm{SO}_{2}$ concentrations in the central part of the Netherlands have decreased steadily since the 1980 s from about $20 \mu \mathrm{gm}^{-3}$ to about $2 \mu \mathrm{gm}^{-3}$ (Figure 1). Sporadic measurements before this period indicate that annual average $\mathrm{SO}_{2}$ concentrations in the 1960s and 1970s were much higher than $20 \mu \mathrm{gm}^{-3}$.

Sulphur emissions have decreased by more than $60 \%$ in Western Europe between the early 1980s and 2000 (Stern, 2006). Sulphur emissions in Eastern Europe generally increased until the late 1980s, and then showed a strong decline coinciding with the collapse of the USSR and the fall of the Berlin Wall. We would expect changes in western European emissions to dominate changes in aerosol concentrations in the Netherlands, especially during westerly

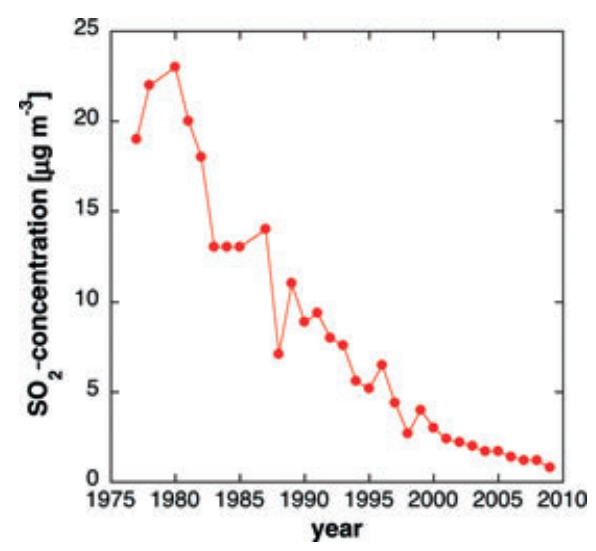

Figure 1. The average yearly sulphur dioxide concentration in the central part of The Netherlands (this area includes Schiphol and De Bilt) between 1976 and 2009, measured by the Dutch national air quality monitoring network (LML), which is operated by RIVM, Bilthoven. Source: CBS, PBL, Wageningen UR, 2011. winds, with emissions from Eastern Europe contributing during periods of easterly winds, and the observations are in good agreement with the trends in emissions. Recent measurements of other important aerosols and precursor gasses (NOx, ammonium, benzenes) show similar decreasing trends in the Netherlands during the brightening period (more data can be found at http://www.compendiumvoordeleefomgeving.nl/dossiers/nl0076-luchtkwaliteitin-Nederland.html?i=14-66).

Although it seems likely that aerosols can explain a large fraction of the visibility variations, meteorological factors such as relative humidity, wind direction and speed, and stability (mixing of the air in the atmosphere) also contribute.

\section{Visibility trends in the Netherlands}

Here we analyse the trends in the frequency of days with high visibility at Schiphol (the main airport in the Netherlands, at $52^{\circ} 18^{\prime} \mathrm{N}$ and $4^{\circ} 46^{\prime} \mathrm{E}$ ) and at De Bilt (the site of the Royal Netherlands Meteorological Institute, the $\mathrm{KNMI}$, at $52^{\circ} 6^{\prime} \mathrm{N}$ and $5^{\circ} 11^{\prime} \mathrm{E}$ ) (Figure 2). These stations are roughly $45 \mathrm{~km}$ apart: Schiphol is about $20 \mathrm{~km}$, and De Bilt about $60 \mathrm{~km}$, from the sea. Reliable measurements of daily maximum visibility at both stations are available since 1955 . The days each year on which the visibility exceeded $19 \mathrm{~km}$ were counted, and separated into continental and maritime wind regimes: the former is defined as a daily average wind direction between east and south $\left(90^{\circ}-180^{\circ}\right)$, whilst all remaining daily average wind directions are classified as maritime.

Figure 3 presents the proportion of days with a maximum visibility greater than $19 \mathrm{~km}$ in each wind regime. This figure remained relatively constant between 1955

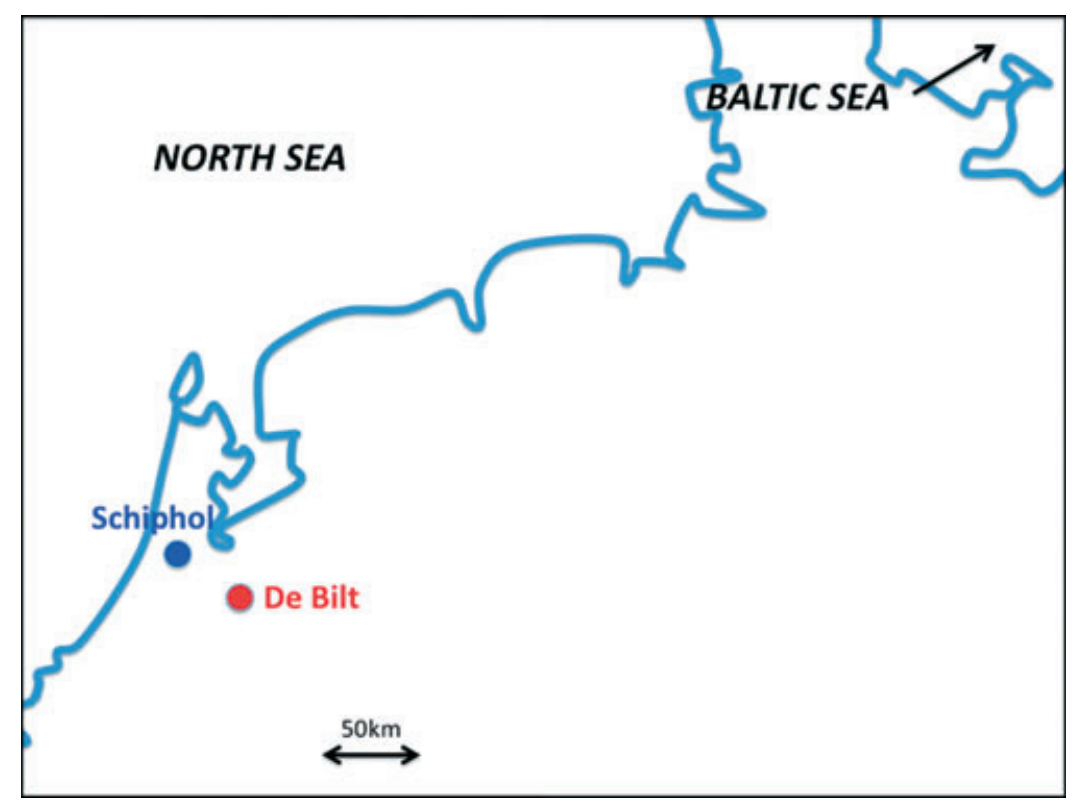

Figure 2. Map of the Netherlands and neighbouring regions. 
and the early 1980s, but has rapidly increased since then, indicating that a spectacular clearing of the air has been occurring in both De Bilt and Schiphol. This seems to have occurred for both continental and maritime winds, although an evaluation of the frequency of days with very high $(>30 \mathrm{~km})$ visibilities reveals that for maritime wind directions the upward curve has levelled off since 2000. This might have been caused by the transition from human observers (who generally report higher visibility) to automatic weather stations (equipped with scattero- and transmissometers) in 2001, or by sea-salt aerosols becoming the limiting factor. The continental visibility profile still shows an upward trend, with the consequence that whereas the visibility on days with winds from the sea was formerly normally greater than on days with winds from the continent, this difference has practically vanished in recent years. Indeed, the frequency of very high $(>30 \mathrm{~km})$ visibility days during continental winds has recently actually surpassed that associated with maritime winds, indicating that the presence of sea salt (in combination with higher relative humidity) during maritime conditions might indeed be a factor limiting the visibility. Continental air masses can have much lower concentrations of
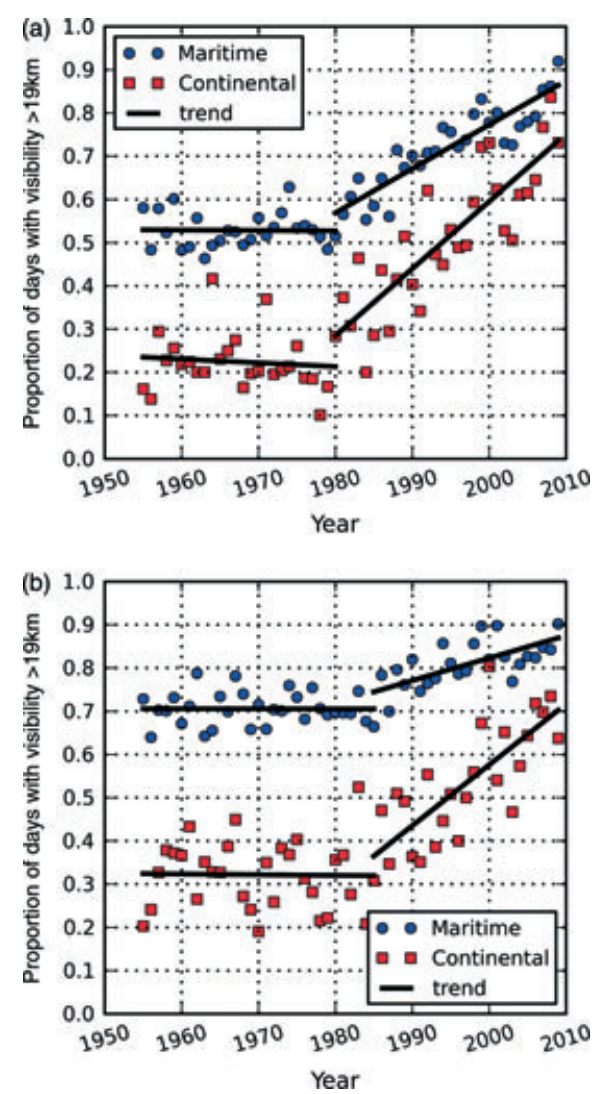

Figure 3. Proportion of days having a maximum visibility greater than $19 \mathrm{~km}$ in each wind regime, i. e. maritime and continental, for each year as observed in De Bilt (a) and Schiphol (b). Least-squares trend lines were drawn to highlight the changes. aerosols, as long as they are not polluted by anthropogenic aerosols. Blowing dust and forest fires can also severely limit the visibility in continental air, but these are relatively rare events in western Europe. The increase in high visibility days corresponds very well with the decrease in low visibility days found in the Netherlands by other studies such as Vautard et al. (2009) and van Oldenborgh et al. (2010). The decreasing SO concentrations are remarkably well-related to the increase of the number of high-visibility days in the Netherlands.

\section{Influence of urbanization, atmospheric circulation and relative humidity}

We need to investigate whether the visibility trends are possibly connected to trends in atmospheric circulation and relative humidity. Atmospheric circulation (wind speed and direction) determines the transport of aerosols and can influence relative humidity. The separation into maritime and continental wind regimes is a crude way of isolating visibility changes from aerosol emissions and atmospheric circulation variations, and gives some information about the emissions in the region where the air comes from. Though yearly variations of the wind regime are fairly large and the data shows some long-term variations, hardly any trend was observed since 1955 or during the dimming and brightening periods. Therefore, it seems unlikely that changes in the wind regime have been an important contributor to the increase in visibility since 1985 .

A decrease in relative humidity has been observed since approximately 1985 in summer (May, June, July and August) between the times of sunrise and sunset both in Schiphol and in De Bilt. However, this does not occur during winter. The daily average rate of decrease of the relative humidity in the four summer months is about $0.25 \%$ per year since 1985 in Schiphol and is particularly strong in the early morning. This change in relative humidity might have contributed to the clearing of the atmosphere in Schiphol. Aerosol size is very sensitive to relative humidity (Ten Brink et al., 1996), in particular to variations in the range $80-100 \%$. The largest fractional change in the number of days with visibility exceeding $19 \mathrm{~km}$ is observed precisely during the early morning and late afternoon when the average relative humidity exceeds $80 \%$ (as discussed below). In De Bilt, however, the decrease in relative humidity since 1985 is much more modest (a decrease of about $0.06 \%$ per year during daytime and an increase of about $0.04 \%$ per year during night-time) and not so strongly correlated with time.

Within a distance of about $10 \mathrm{~km}$ the environment of the measuring site in De Bilt has hardly changed since 1985 , while the airport of Schiphol has grown strongly. Since the 1970s, a large expansion of the built-up area (including office buildings, hotels, hangars and additional airstrips) at the airport has taken place. The number of passengers going through Schiphol per year has increased from about 1 million in 1960, to 10 million in 1980 and to 45 million in 2010. It is, therefore, likely that the growth of the airport has made the climate in Schiphol more 'urban', especially reducing evaporation and lifting night-time temperatures. Since 1985 summer night-time temperatures have indeed risen much more at the measuring site of Schiphol than at most other measuring sites in The Netherlands, which show similar trends to those at De Bilt.

\section{Trends in cloudiness, sunshine and global short-wave radiation}

Besides leading to a better visibility (a direct aerosol effect), a decrease in aerosol concentration might also lead to a reduction in cloudiness (indirect aerosol effect). The sunshine duration measurements ${ }^{1}$, which are considered to be more accurate than cloud cover estimates, can be used as a good proxy of (daytime) cloudiness. The trends of yearly average daily sunshine duration (Figure 4), presented as a percentage of the day length, in both De Bilt and Schiphol show a similar pattern to the trends in high visibility days, and are consistent with what is expected from both the aerosol direct and indirect effect. Since the early 1980s, the sunshine frequency has increased by as much as $25 \%$.

This trend is, however, occurring almost exclusively in summer: between 1985 and

${ }^{1}$ At Schiphol, data was missing during a large part of the summer of 1967 and the data before that date was left out for convenience. The change in sunshine recording from Campbell-Stokes to pyranometers between 1991 and 1993 is not clearly reflected in the yearly average sunshine duration.

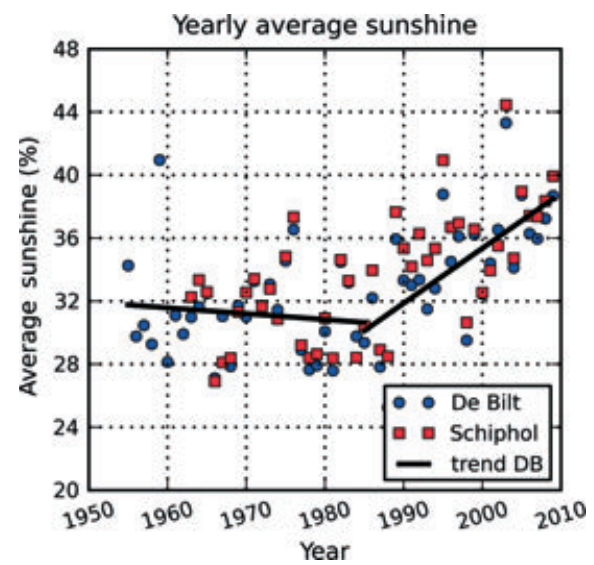

Figure 4. Sunshine duration as a percentage of the day length at De Bilt and Schiphol. 
2010, the average value of the surface global short-wave radiation in De Bilt in summer has increased by more than $15 \mathrm{Wm}^{-2}$ (i.e. $0.6 \mathrm{Wm}^{-2} \mathrm{yr}^{-1}$ ). The average level of the surface global short-wave radiation in summer for this period is $194.7 \mathrm{Wm}^{-2}$, compared with $188.7 \mathrm{Wm}^{-2}$ for the dimming period between 1958 and 1983. The increase during the brightening period is strongest in the morning, between 0700 and 1000 UTC, at more than $1.5 \mathrm{Wm}^{-2} \mathrm{yr}^{-1}$. We will see in the next section that this trend is reflected in summer in both the daily cycle of the trend in the number of high visibility days as well as in the daily cycle of the trend in the temperature during this period.

\section{Visibility, aerosol loading and temperature}

Upward trends in visibility are also occurring in other parts of Europe. Vautard et al. (2009) conclude that the reduction in low visibility conditions could have contributed up to $20 \%$ of the recent daytime warming in Europe, while Wild et al. (2007) concluded that aerosols have reduced global surface warming between 1955 and 1985 possibly by as much as $60-70 \%$. Figure 5 displays the evolution of the average yearly temperature in De Bilt during two periods of 26 years. The first period (the dimming period) runs from 1958 to 1983 , the second period (the brightening period) runs from 1985 to 2010. A linear regression of the temperature with respect to time, for the two periods separately, demonstrates that the temperature trend has been $0.022^{\circ} \mathrm{C}$ per year in the first period, while it has doubled to $0.044^{\circ} \mathrm{C}$ per

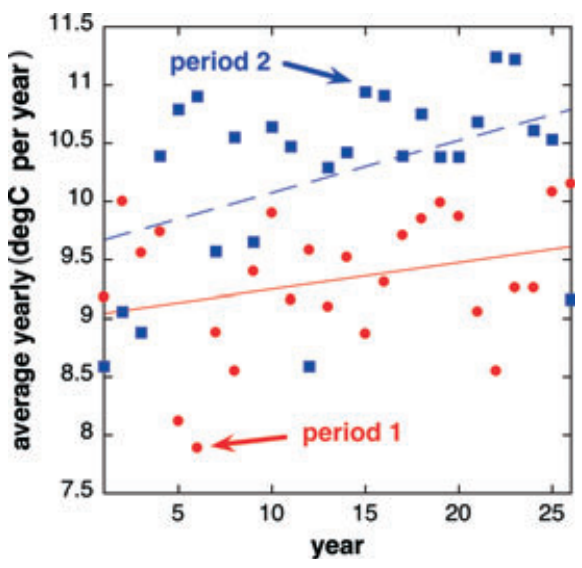

Figure 5. The average yearly temperature in De Bilt during two periods of 26 years. Period 1 runs from 1958 (year 1) to 1983 (year 26); period 2 runs from 1985 (year 1) to 2010 (year 26). The straight lines represent linear regressions for the two periods. The variance of the temperature around the mean is large during both periods $(R=0.30$ and 0.44 respectively). Nevertheless, the acceleration of the warming in the second period is significant. The trend in period 1 (period 2) is $0.022^{\circ} \mathrm{C}$ per 24 year $\left(0.044^{\circ} \mathrm{C}\right.$ per year). year in the second period. The temperature trends are strikingly similar to those in both the visibility (Figure 3 ) and the sunshine duration (Figure 4). It is, therefore, useful to investigate further the possible link between warming and the decreased aerosol loading.

Using the hourly observations from De Bilt we performed separate linear regressions of the average summer and winter temperatures for each hour of the day. As before, the summer is defined as comprising the months of May, June, July and August, i.e. 123 days. The winter is defined as comprising the months of November, December, January and February, i.e 120 days, not counting 29 February. We did this for two separate periods of 26 years. The first winter in the first period is the winter of 1957-1958, while the first summer is that of 1958; the first winter in the second period is the winter of 1984-1985, and the first summer that of 1985.

Figure 6 demonstrates that the accelerated warming during the brightening period is observed only in summer during daytime. In winter the temperature timetrend hardly shows a daily cycle. Neither does it show a clear change between the first and the second period. Other processes than the aerosol effects on solar radiation, such as the anthropogenic greenhouse effect, or possibly changes in atmospheric circulation, dominate the warming trend because solar irradiance is small in winter (e.g. van Oldenborgh et al., 2009). In summer we observe a spectacular change in the temperature trend during daylight hours (0500-1900 UTC) in De Bilt, especially during the morning hours (0600-1000 UTC): the mornings have been getting warmer at a rate which equates to an impressive $7 \mathrm{deg} C$ per century!

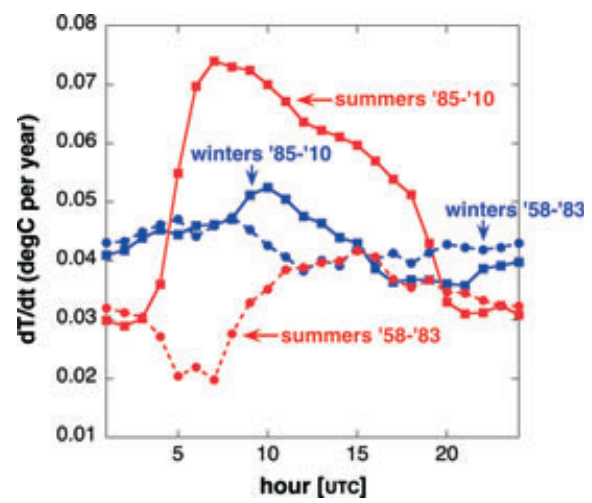

Figure 6. The daily cycle in the linear trend in temperature in De Bilt during two periods of 26 years, for the winter and the summer, respectively. No significant daily cycle is observed in the winters, while the summers in the second period show a strong daily cycle which could be due to the change in both the direct and indirect aerosol effect, since aerosol concentrations have changed strongly during this period.
Although there is hardly any significant trend in yearly average relative humidity or in cloudiness during the dimming and brightening periods, significant changes in these variables are found as a function of the time of the day. The strong warming during summer days during the brightening period is consistent with what we find from the trends in relative humidity (Figure 7) and visibility (Figure 8). The clearing of the atmosphere during this period, both in terms of increasing visibility and in terms of decreasing cloudiness, is much less strong in winter than in summer: visibility has increased in winter since 1985 by about half the rate observed in summer. At the same time relative humidity has increased in winter since 1985 (Figure 7). So, in winter there are two competing effects on visibility, namely increasing relative humidity, reducing visibility, and decreasing aerosol-loading enhancing visibility. Apparently, the aerosol effect on visibility dominates. During summer nights and during winter (day and night) relative humidity is usually at levels (>80\%) where

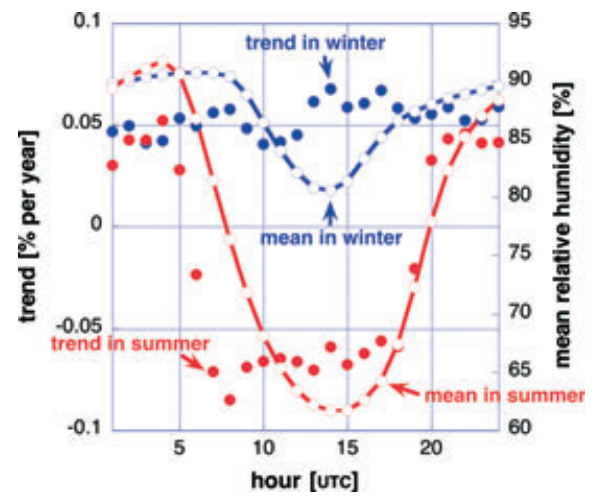

Figure 7. Daily cycle of the relative humidity during summer and winter in the brightening period (1985-2010) in De Bilt and the associated linear trend during this period.

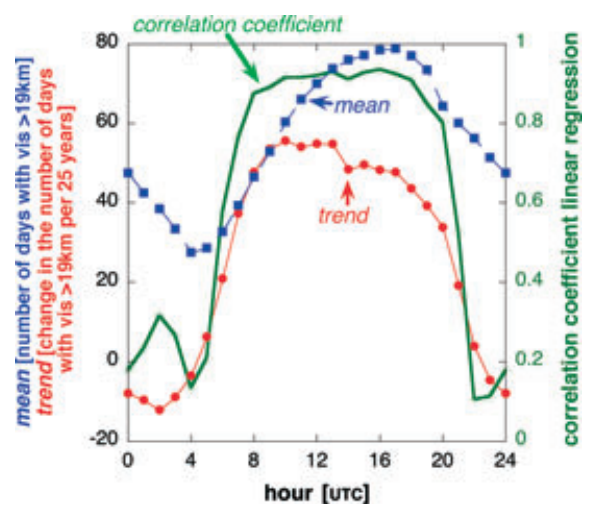

Figure 8. Daily cycle of the average number of days with visibility greater than $19 \mathrm{~km}$ during summer (123 days) in period 2 (1985-2010) in De Bilt and the associated linear trend during this period. The linear regression correlation coefficient $(R)$ is also presented as a measure of the statistical significance of the trend. 
visibility is very sensitive to changes in relative humidity.

Figure 8 demonstrates that the clearing of the atmosphere is occurring in summer only during daytime. Visibility has changed relatively most strongly in the morning. Visibility has hardly changed during the night, probably because of the competing effect of increasing relative humidity (which, again, is much more important at night than during daytime).

The aerosol indirect effect on clouds can also influence global radiation, so it is necessary to look at changes in cloud cover. Cloud-cover measurements have been obtained by human observers and by ceilometers. Both generally report significantly different values. To remove some of this bias we have plotted the average fraction of the day and night during which partly cloudy and clear conditions occur (cloud cover between 0 and 2 octas). We have done this for the summer months when largest trends in global radiation, in relative humidity and in visibility were observed. It appears that cloud cover has decreased during both day and night (Figure 9); the change has been significantly larger for daytime cloudiness than for night-time cloudiness, which is similar to the changes in relative humidity and visibility. This can probably partly be attributed to the indirect aerosol effect and the decrease in relative humidity. From both effects we expect fewer morning fogs (which has been observed, e.g. Vautard et al. (2009), Oldenburgh et al. (2010)) and possibly suppression or later formation and earlier dissipation of midday cumulus convection. It should be noted that the

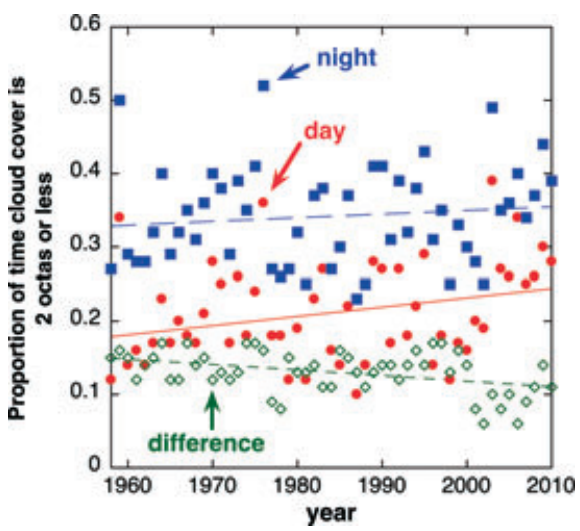

Figure 9. The proportion of the day (06001800 UTC) and night (1900-0500 UTC) during which the cloud fraction is between 0 and 2 octas (i.e. clear and partly cloudy skies) in the summer months (May to August). trends in cloud cover are highly uncertain (the record is inhomogeneous), and the linear regression coefficient is also below 0.3 . The summer daytime trends in visibility are however highly significant $(R=0.9)$. Besides that, we do not find a significant 'jump' in the cloud cover trends around 1985 similar to the ones we see for visibility and sunshine duration. This 'jump' however can also be found in the global radiation trends, suggesting that the aerosol direct effect dominates the trends in solar radiation at the surface during the brightening period.

All these changes during daytime are leading to an increase in surface solar radiation. This is confirmed by the measurements of global short-wave radiation at De Bilt, which show that this has steadily increased in summer but changed little in winter. It is likely that this effect is responsible for a significant part of the daytime upward temperature trend in summer, which is reflected also in an accelerated increase of the yearly average temperature after 1985. Nevertheless, we should not jump to conclusions too easily. Apparent agreement between trends does not imply causality. Possible causal links can only be identified by a model study in combination with an analysis of observations.

\section{Summary}

A major clearing of the air has occurred in the Netherlands in the past few decades. These changes are so large that they have become very obvious when looking at the data of individual stations. Strong indications can be found linking human emissions of aerosols to the visibility changes. Coincident with the visibility changes, large trends in cloud cover, sunshine duration and temperature are found, in particular during daytime in summer, showing that these tiny particles might have a significant influence on regional climate.

\section{Acknowledgements}

The data used were obtained from Koninklijk Nederlands Meteorologisch Instituut (KNMI), http://www.knmi.nl/klimatologie/

\section{References}

Cass GR. 1979. On the relationship between sulphate air quality and visibility with examples in Los Angeles. Atmos. Environ. 13: 1069-1084.

CBS, PBL, Wageningen UR. 2011. Zwaveldioxideconcentratie, 1990-2010 (indicator 0441, versie 08, 14 April 2011). http://www.compendiumvoordeleefomgeving.nl/. CBS: Den Haag; Planbureau voor de leefomgeving, Den Haag/Bilthoven en Wageningen UR, Wageningen.

Doyle M, Dorling S. 2002. Visibility trends in the UK, 1950-1997. Atmos. Environ. 36: 3161-3172.

Gomez B, Smith CG. 1987. Visibility at Oxford, 1926-1985. Weather 42: 98-106. Horvath H. 1981. Atmospheric visibility. Atmos. Environ. 15: 1785-1796.

Ohmura A, Lang H. 1989. Secular variation of global radiation over Europe, in Current Problems in Atmospheric Radiation. Lenoble J, Geleyn JF (eds). Deepak: Hampton, VA, pp 98-301.

van Oldenborgh GJ, Drijfhout SS, van Ulden AP, Haarsma R, Sterl A, Severijns C, Hazeleger W, Dijkstra HA. 2009. Western Europe is warming much faster than expected. Clim. Past 5: 1-12. http:// www.clim-past.net/5/1/2009/cp-5-1-2009. pdf.

van Oldenborgh GJ, Yiou P, Vautard R. 2010. On the roles of circulation and aerosols in the decline of mist and dense fog in Europe over the last 30 years. Atmos. Chem. Phys. 10: 4597-4609. doi:10.5194/ acp-10-4597-2010.

Stern DI. 2006. Reversal of the trend in global anthropogenic sulfur emissions. Global Environ. Change 16: 207-220. doi:10.1016/j.gloenvcha.2006.01.001.

Ten Brink HM, Veefkind JP, Waijersljpelaan A, van der Hage JC. 1996. Aerosol light scattering in The Netherlands. Atmos. Environ. 30: 4251-4261.

Vautard R, Yiou P, van Oldenborgh GJ. 2009. Decline of fog, mist and haze in Europe over the past 30 years. Nat. Geosci. 2: 2115-2119. doi:10.1038/ngeo414.

Wang KC, Dickinson RE, Liang SL. 2009. Clear sky visibility has decreased over land globally from 1973 to 2007 . Science 323(5920): 1468-1470. doi:10.1126/ science. 1167549

Wild M. 2009. Global dimming and brightening: a review. J. Geophys. Res. 114: D00D16. doi:10.1029/2008JD01 1470. Wild M, Ohmura A, Makowski K. 2007. Impact of global dimming and brightening on global warming. Geophys. Res. Lett. 34: L04702. doi:10.1029/2006GL028031.

Correspondence to: A. J. van Beelen

A.J.vanBeelen@uu.nl

(C) Royal Meteorological Society, 2012

DOI: $10.1002 /$ wea.854 